\title{
Oxygen saturation during daily activities in chronic obstructive pulmonary disease
}

\author{
N. Soguel Schenkel, L. Burdet, B. de Muralt, J.W. Fitting
}

\begin{abstract}
Oxygen saturation during daily activities in chronic obstructive pulmonary disease. $N$. Soguel Schenkel, L. Burdet, B. de Muralt, J.W. Fitting. (CERS Journals Ltd 1996.

ABSTRACT: Patients with chronic obstructive pulmonary disease (COPD) frequently develop nocturnal oxygen desaturation because of alveolar hypoventilation, worsening of ventilation-perfusion mismatch, and sometimes obstructive sleep apnoeas. In contrast, little is known about their oxygen status during the various activities of daily life. The aim of this study was to compare the oxygen saturation profile during day and night, and to assess the influence of different daily activities in COPD.

During a rehabilitation programme, we studied 30 patients with moderate-tosevere COPD (median forced expiratory volume in one second (FEV1) 37\% of predicted), without marked hypoxaemia (median arterial oxygen tension $\left(\mathrm{Pa}_{\mathrm{a}}, \mathrm{O}_{2}\right) 9.1$ $\mathrm{kPa})$. Arterial oxygen saturation $\left(\mathrm{S}_{\mathrm{a}}, \mathrm{O}_{2}\right)$ was assessed by pulse oximetry during night $(8 \mathrm{~h})$ and day $(10.5 \mathrm{~h})$. The mean and minimal $\mathrm{Sa}_{\mathrm{a}} \mathrm{O}_{2}$ were calculated, and desaturations were defined as $S \mathrm{a}, \mathrm{O}_{2}$ falls $>4 \% \cdot \mathrm{h}^{-1}$. Daily activities were identified by the patients as resting, eating, washing, nebulization therapy and walking.

Mean $\mathrm{Sa}_{\mathrm{a}} \mathrm{O}_{2}$ was lower during the night $(88 \%)$ than during the day $(89 \%)$. In contrast, minimal $\mathrm{Sa}_{\mathrm{a}, \mathrm{O}_{2}}$ was lower during the day $(69 \%)$ than during the night $(72 \%)$, and the number of desaturations was higher during the day (8.6 desaturations $\left.\cdot h^{-1}\right)$ than during the night (6.8 desaturations $\left.\cdot h^{-1}\right)$. Mean $\mathrm{Sa}_{\mathrm{a}} \mathrm{O}_{2}$ was $88 \%$ during walking, which was lower than during resting $(90 \%)$, nebulization $(90 \%)$, and meals $(89 \%)$. The number of desaturations was higher during walking (13.1 desaturations $\left.\cdot h^{-1}\right)$, washing $\left(12.6\right.$ desaturations $\left.\cdot h^{-1}\right)$, and eating $\left(9.2\right.$ desaturations $\left.\cdot h^{-1}\right)$ than during resting $\left(5.3\right.$ desaturations $\left.\cdot h^{-1}\right)$.

We conclude that daily activities, such as walking, washing and eating, are associated with transient oxygen desaturation in patients with moderate-to-severe chronic obstructive pulmonary disease, even without marked resting hypoxaemia. Eur Respir J., 1996, 9, 2584-2589.
\end{abstract}

Patients suffering from chronic obstructive pulmonary disease (COPD) progressively develop arterial hypoxaemia leading to pulmonary hypertension, cor pulmonale and death. In these patients, survival can be prolonged by long-term oxygen therapy $[1,2]$. Guidelines for patients qualifying for long-term oxygen therapy generally include an arterial oxygen tension $\left(\mathrm{Pa}, \mathrm{O}_{2}\right)$ less than 7.3 $\mathrm{kPa}(55 \mathrm{mmHg})$. During recent years, transcutaneous oximetry has become widely available, allowing monitoring of oxygen saturation. Continuous oximetry recordings complement the punctual measurement of arterial blood gas values for assessing oxygen status, and may eventually lead to a modification of the criteria for longterm oxygen therapy. Thus, development or worsening of hypoxaemia during sleep has been well-documented in patients with COPD [3-7], and is associated with cardiac arrhythmia $[8,9]$ and pulmonary hypertension $[10$, 11]. Nocturnal oxygen desaturation also occurs in approximately a quarter of COPD patients with diurnal $\mathrm{Pa}_{\mathrm{a}} \mathrm{O}_{2}$ greater than $8.0 \mathrm{kPa}(60 \mathrm{mmHg})[12]$, being associated with increased pulmonary arterial pressure [13] and a shorter survival [14]. Pulmonary arterial pressure can be reduced by nocturnal supplemental oxygen in these patients [15].
Centre de réhabilitation respiratoire, Hôpital régional, Rolle, and Division de pneumologie, Centre Hospitalier Universitaire Vaudois, Lausanne, Switzerland.

Correspondence: J.W. Fitting

Division de pneumologie

CHUV

1011 Lausanne

Switzerland

Keywords: Haemoglobin obstructive lung disease oxygen

saturation

Received: March 221996

Accepted after revision August 251996
Although the nocturnal profile of arterial oxygen saturation is well-described in COPD, the evolution of oxygen saturation throughout the day is only scarcely documented. In three studies, two in COPD $[16,17]$ and one in cystic fibrosis [18], diurnal arterial oxygen saturation $\left(\mathrm{Sa}_{\mathrm{a}} \mathrm{O}_{2}\right)$ was recorded for a short while at rest, and was found to correlate weakly with nocturnal $\mathrm{Sa}_{\mathrm{a}} \mathrm{O}_{2}$. To our knowledge, only two studies have recorded $\mathrm{Sa}_{2} \mathrm{O}_{2}$ over a $24 \mathrm{~h}$ period in COPD. These patients were receiving long-term oxygen therapy, and manifested the most severe desaturations either during sleep [19] or during exercise [20]. The aim of the present study was to compare diurnal and nocturnal $\mathrm{Sa}_{2} \mathrm{O}_{2}$ profiles in moderateto-severe COPD patients not receiving supplemental oxygen, and to determine the influence of different daily activities on $\mathrm{Sa}_{\mathrm{a}} \mathrm{O}_{2}$.

\section{Material and methods}

\section{Study subjects}

All patients with COPD in a stable clinical state, who were admitted to the Centre of Pulmonary Rehabilitation 
of Rolle between 1 November 1994 and 31 March 1995, were considered for the study. Patients with moderateto-severe COPD (forced expiratory volume in one second (FEV1) $<70 \%$ of predicted), according to the definition and the criteria set forth by the European Respiratory Society [21], were included. As the study required active collaboration, patients with poor motivation were excluded. Six patients were excluded because of technical problems during oximetry.

A total of 30 patients fulfilled these criteria and were analysed in this study. At admission, none of the patients was on long-term oxygen therapy, but three were administered nocturnal oxygen during the pulmonary rehabilitation programme. The physical characteristics, spirometry and arterial blood gas values of the 30 patients are presented in table 1 . None of them was darkpigmented or jaundiced. Most of the patients were males $(77 \%)$. Sixteen patients were overweight (body mass in$\operatorname{dex}(\mathrm{BMI})>25 \mathrm{~kg} \cdot \mathrm{m}^{-2}$ ) and three were underweight (BMI $<20 \mathrm{~kg} \cdot \mathrm{m}^{-2}$ ). Twenty four patients were ex-smokers $(80 \%)$ and six were current smokers at the time of the study. Six patients had $\mathrm{Pa}, \mathrm{O}_{2}<8.0 \mathrm{kPa}(60 \mathrm{mmHg})$ and seven had arterial carbon dioxide tension $\left(\mathrm{Pa}_{\mathrm{a}} \mathrm{CO}_{2}\right)>6.0$ $\mathrm{kPa}(45 \mathrm{mmHg})$ at rest.

\section{Study design}

Pulse oximetry was recorded during the day from 06:00 $\mathrm{h}$ to $18: 00 \mathrm{~h}$, and during the night from bedtime to 06:00 $\mathrm{h}$ the next morning. Records were performed during the last week of stay, after at least 2 weeks of rehabilitation. Daytime and nocturnal oximetry took place on the same day in 18 patients, on two successive days in six patients, within 3 days in four patients, within 4 days in one patient and within 5 days in one patient. During diurnal oximetry, the patients were asked to fill in a form listing their different activities according to the hour of the day: resting, eating, washing, nebulization therapy, walking. All periods of walking lasting more than 5 min were listed. Nebulization therapy consisted of a mixture of salbutamol and ipratropium bromide delivered by air-driven nebulizers.

Table 1. - Physical characteristics, spirometry, and arterial blood gas values of 30 patients

\begin{tabular}{|c|c|c|}
\hline Age yrs & 67 & $(49-78)$ \\
\hline Gender $\mathrm{M} / \mathrm{F}$ & $23 / 7$ & \\
\hline Weight kg & 70.7 & $(50-124)$ \\
\hline Height $\mathrm{cm}$ & 169 & $(152-183)$ \\
\hline $\mathrm{BMI} \mathrm{kg} \cdot \mathrm{m}^{-2}$ & 25.5 & $(17.7-42.5)$ \\
\hline FEV1 \% pred & 37 & $(16-64)$ \\
\hline FEV1/FVC \% & 42 & $(20-64)$ \\
\hline $\mathrm{Pa}_{\mathrm{a}, \mathrm{O}_{2}} \quad \mathrm{kPa}$ & 9.1 & $(7.2-11.9)$ \\
\hline \multirow{3}{*}{$\begin{array}{l}\mathrm{mmHg} \\
\mathrm{kPa} \\
\mathrm{mmHg}\end{array}$} & 68 & $(54-89)$ \\
\hline & 5.6 & $(4.7-6.8)$ \\
\hline & 42 & $(35-51)$ \\
\hline
\end{tabular}

Values are median and range in parenthesis. M: male; F: female; BMI: body mass index; FEV1: forced expiratory volume in one second; FVC: forced vital capacity; $\%$ pred: percentage of predicted value; $\mathrm{Pa}_{\mathrm{a}} \mathrm{O}_{2}$ : arterial oxygen tension; $\mathrm{Pa}_{\mathrm{a}} \mathrm{CO}_{2}$ : arterial carbon dioxide tension.

\section{Methods}

Diurnal and nocturnal oximetry were performed with a pulse oximeter (Vitalog, Reedwood City, USA) which recorded arterial haemoglobin saturation and heart rate every $2 \mathrm{~s}$. This oximeter is supplied with a battery and is portable to the belt, thereby affording independence. The digital probe was attached to the left hand for righthanded patients and to the right hand for left-handed patients. The probe was attached to the finger and secured to the wrist. Radial arterial blood was sampled at rest while breathing room air, and immediately analysed for $\mathrm{pH}$, oxygen tension $\left(\mathrm{PO}_{2}\right)$ and carbon dioxide tension $\left(\mathrm{PCO}_{2}\right)$ by a blood gas analyser (AVL $995 \mathrm{~S}$; Graz, Austria). Spirometry was performed with a mass flow sensor (SensorMedics 2200 TP, Yorba Linda, CA, USA) within 4 days of diurnal oximetry.

\section{Analysis}

The Vitalog analysis programme provided both numerical results and graphic display. Mean $\mathrm{Sa}_{\mathrm{a}} \mathrm{O}_{2}$, minimal $\mathrm{Sa}_{\mathrm{a}} \mathrm{O}_{2}$, and the number desaturations (a desaturation was defined as a drop in $\mathrm{Sa}_{2} \mathrm{O}_{2}$ at least $4 \%$ followed by a rise of at least $4 \%$ ) were calculated for the entire recording period or for a part of it that could be selected on the graphic display. The latter showed $\mathrm{Sa}_{2} \mathrm{O}_{2}$ and heart rate as a function of time. In order to minimize possible artefacts during diurnal oximetry, we excluded every period during which heart rate fell abruptly by more than 25 beats. $\min ^{-1}$ (one square on the graph).

The mean $\mathrm{Sa}_{2} \mathrm{O}_{2}$, the minimal $\mathrm{Sa}_{\mathrm{a}} \mathrm{O}_{2}$ and the number of desaturations per hour were compared between diurnal and nocturnal oximetry using the Wilcoxon signedrank test. For each patient, the mean $\mathrm{S}_{\mathrm{a}} \mathrm{O}_{2}$, the minimal $\mathrm{Sa}, \mathrm{O}_{2}$ and the number of desaturations per hour were averaged during five different diurnal activities: resting, eating, washing, nebulization therapy and walking. The results were compared between these five activities using the Friedman test, followed by comparisons among pairs of means using Wilcoxon signed-rank test with Hochberg correction for multiple comparisons [22]. Linear regression analysis was performed between mean $\mathrm{Sa}_{\mathrm{a}} \mathrm{O}_{2}$ at rest and the minimal $\mathrm{Sa}_{\mathrm{a}} \mathrm{O}_{2}$, and the number of desaturations, during meals, washing and walking.

\section{Results}

Diurnal and nocturnal oximetry data are presented in table 2. Artefacts, as defined earlier by an abrupt drop of heart rate, were mostly observed during activities associated with motion: walking, washing, eating, in decreasing order of frequency. The mean recording time of diurnal oximetry was $693 \pm 88 \mathrm{~min}(11.6 \mathrm{~h})$. After exclusion of all periods considered to contain artefacts, the mean duration of diurnal oximetry available for analysis was $630 \pm 95 \mathrm{~min}(10.5 \mathrm{~h})$. The mean recording time of nocturnal oximetry was $482 \pm 11 \mathrm{~min}(8 \mathrm{~h})$. No period of nocturnal oximetry was excluded, because artefacts were minimal.

Considering the 27 patients who were not receiving supplemental oxygen, the mean $\mathrm{Sa}_{\mathrm{a}} \mathrm{O}_{2}$ was lower during the night, median $88 \%$ (range $80-94 \%$ ), than during the 
Table 2. - Oximetry data

\begin{tabular}{lccccr}
\hline Activity & $\mathrm{n}$ & $\begin{array}{c}\text { Duration\# } \\
\text { min }\end{array}$ & $\begin{array}{c}\text { Mean } \mathrm{Sa}_{\mathrm{a}, \mathrm{O}_{2}}{ }^{*} \\
\%\end{array}$ & $\begin{array}{c}\text { Minimal } \mathrm{Sa}_{\mathrm{a}, \mathrm{O}_{2}} \\
\%\end{array}$ & $\begin{array}{c}\mathrm{S}_{\mathrm{a}, \mathrm{O}_{2}} \\
\text { desaturations} \cdot \mathrm{h}^{-1}\end{array}$ \\
\hline Nocturnal oximetry & 27 & $482.5(11.0)$ & $88.5(79.5-93.5)$ & $72.0(49.0-84.0)$ & $6.8(1.2-18.2)$ \\
Daytime oximetry & 27 & $629.6(95.2)$ & $89.0(82.5-95.6)$ & $69.0(33.0-78.0)$ & $8.6(3.0-39.4)$ \\
Resting & 29 & $315.2(103.0)$ & $90.5(81.3-95.7)$ & $75.0(53.0-81.0)$ & $6.1(3.8-19.6)$ \\
Eating & 30 & $64.5(21.7)$ & $89.5(83.0-95.2)$ & $77.0(52.0-86.0)$ & $8.5(1.4-34.5)$ \\
Washing & 27 & $22.3(9.9)$ & $87.4(81.1-94.4)$ & $79.0(63.0-88.0)$ & $12.8(0.0-46.2)$ \\
Nebulization & 28 & $39.2(18.4)$ & $89.9(80.3-95.8)$ & $80.5(59.0-89.0)$ & $7.3(0.0-25.8)$ \\
Walking & 25 & $50.4(34.1)$ & $87.6(82.3-94.7)$ & $76.0(47.0-83.0)$ & $14.3(2.7-46.7)$ \\
\hline
\end{tabular}

\#: values are presented as mean, and SD in parenthesis; recording time during each activity after exclusion of artefacts; $\mathrm{S}_{\mathrm{a}, \mathrm{O}_{2}}$ : arterial oxygen saturation.

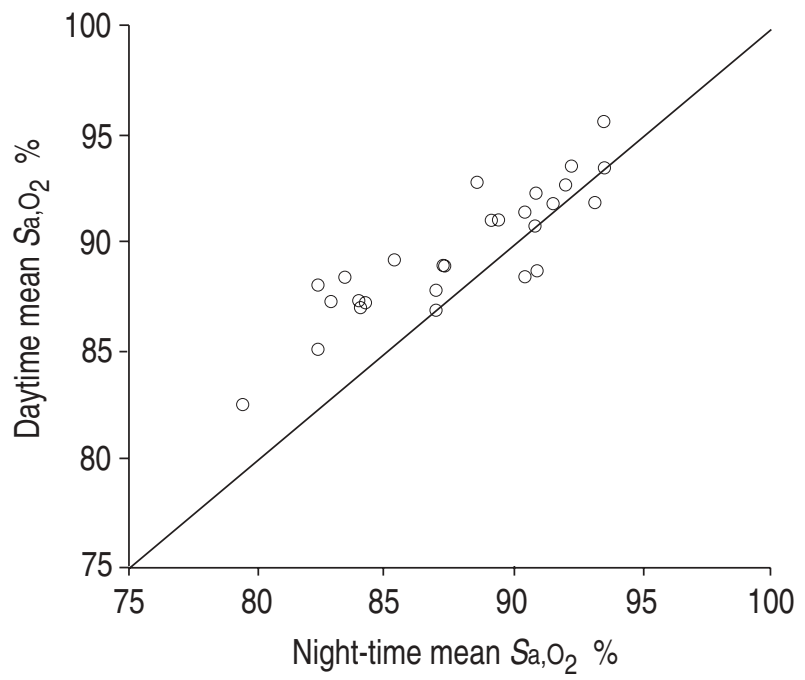

Fig. 1. - Relationship between diurnal and nocturnal mean arterial oxygen saturation $\left(\mathrm{S}_{\mathrm{a}, \mathrm{O}_{2}}\right)$ in 27 patients with chronic obstructive pulmonary disease (COPD) not receiving supplemental oxygen. The line of identify is shown.

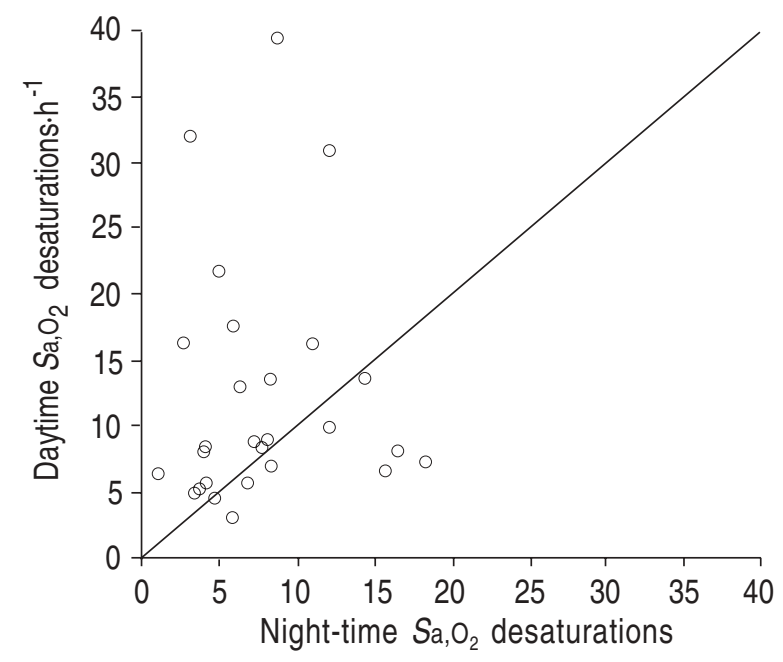

Fig. 2. - Relationship between the number of desaturations per hour during the day and the night in 27 patients with chronic obstructive pulmonary disease (COPD) not receiving supplemental oxygen. The line of identity is shown. $\mathrm{Sa}_{\mathrm{a}, \mathrm{O}_{2}}$ : arterial oxygen saturation (a desaturation is defined as a drop of at least $4 \%$ followed by a rise of at least $4 \%$ ).

day, $89 \%(82-96 \%)(\mathrm{p}<0.001)$ (fig. 1). In contrast, the minimal $\mathrm{Sa}_{\mathrm{a}} \mathrm{O}_{2}$ was lower during the day, 69\% (33-78\%), than during the night, $72 \%(49-84 \%)(p<0.05)$. Furthermore, the number of desaturations per hour was higher during the day, $8.6(3.0-39.4)$, than during the night, $6.8 \%(1.2-18.2 \%)(\mathrm{p}<0.05)$ (fig. 2$)$.
During daytime activities, the mean $\mathrm{Sa}_{\mathrm{a}} \mathrm{O}_{2}$ was highest during rest and lowest during washing (table 2). The minimal $\mathrm{Sa}_{\mathrm{a}} \mathrm{O}_{2}$ was highest during nebulization therapy, and was lowest during resting and walk. The number of desaturations was small during rest and nebulization therapy, and was large during washing and walking. However, it should be noted that not all patients could be recorded during all activities.

Oximetry was recorded during all five daytime activities in 20 patients, thus allowing statistical comparisons (fig. 3 and 4). The mean $\mathrm{Sa}_{\mathrm{a}} \mathrm{O}_{2}$ was $87.5 \%$ (median) during walking, which was significantly lower than during rest $(89.9 \% ; \mathrm{p}<0.05)$ (fig. 5), nebulization therapy $(89.9 \% ; \mathrm{p}<0.05)$, and meals $(88.8 \% ; \mathrm{p}<0.05)$. The mean $\mathrm{Sa}_{\mathrm{a}} \mathrm{O}_{2}$ was also lower during washing $(88.6 \%)$ than during nebulization therapy $(89.9 \%$; $<<0.05)$. The minimal $\mathrm{Sa}, \mathrm{O}_{2}$ was similar for the different activities, except for nebulization therapy $(81.5 \%)$ during which it was significantly higher than during rest $(74.5 \% ; \mathrm{p}<0.05)$, meals $(76.5 \% ; \mathrm{p}<0.05)$, and walking $(76.5 \% ; \mathrm{p}<0.05)$. The number of desaturations was higher during walking (13.1 desaturations $\left.\cdot \mathrm{h}^{-1}\right)$, washing (12.6 desaturations $\left.\cdot \mathrm{h}^{-1}\right)$, and meals $\left(9.2\right.$ desaturation $\left.\cdot h^{-1}\right)$ than during rest $(5.3$ desaturations $\left.\cdot h^{-1} ; \mathrm{p}<0.05\right)$. The number of desaturations during walking was also higher than during nebulization therapy (5.5 desaturations $\left.\cdot \mathrm{h}^{-1} ; \mathrm{p}<0.05\right)$.

Significant correlations were found between resting mean $\mathrm{Sa}_{\mathrm{a}} \mathrm{O}_{2}$ and the minimal $\mathrm{Sa}, \mathrm{O}_{2}$ during meals ( $\mathrm{r}=0.649$;

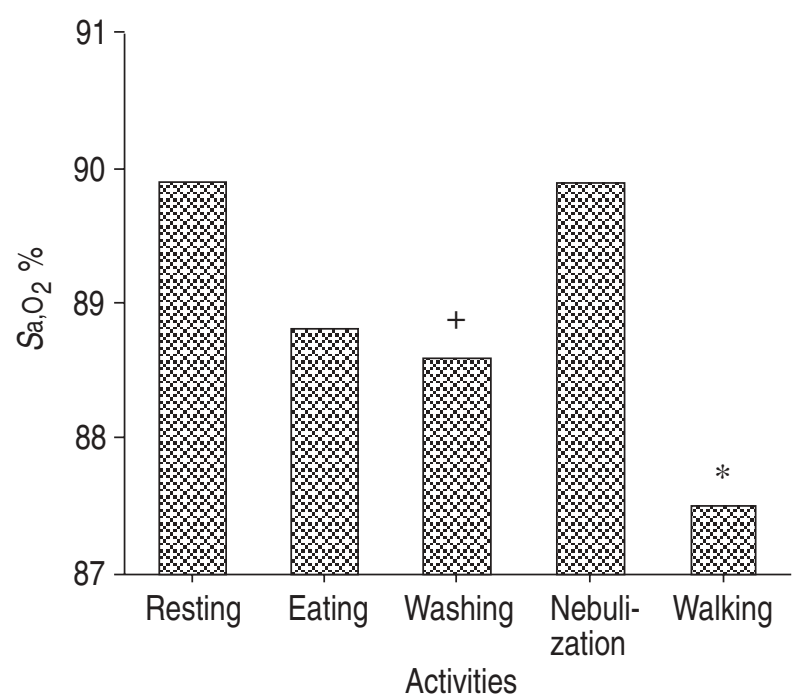

Fig. 3. - Median values of mean oxygen saturation during five daytime activities in 20 patients with chronic obstructive pulmonary disease (COPD). $\mathrm{Sa}_{\mathrm{a}, \mathrm{O}_{2}}$ : arterial oxygen saturation. *: $\mathrm{p}<0.05$ vs oxygen saturation during rest, meals and nebulization; $+: \mathrm{p}<0.05$ vs oxygen saturation during nebulization. 


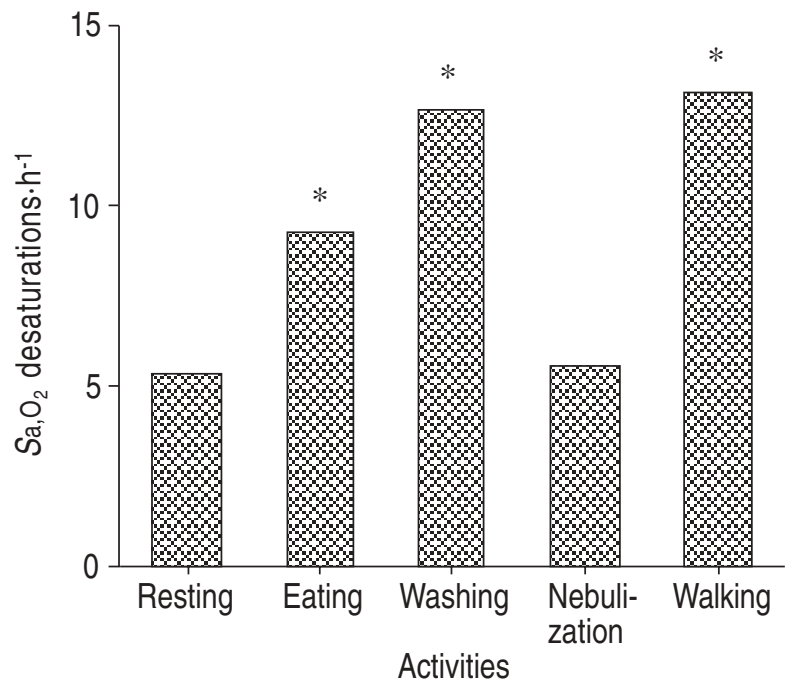

Fig. 4. - Median values of number of desaturations $\left(\mathrm{Sa}_{\mathrm{a}} \mathrm{O}_{2}\right.$ falls $\left.>4 \%\right)$ per hour during five daytime activities in 20 patients with chronic obstructive pulmonary disease (COPD). *: $\mathrm{p}<0.05$ vs number of desaturations during rest. For definitions see legend to figure 2 .

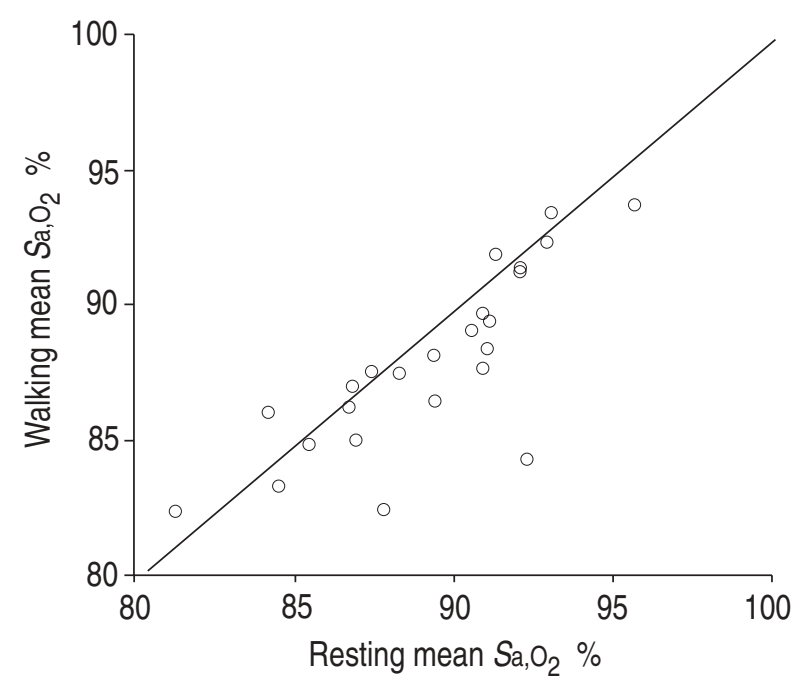

Fig. 5. - Relationship between mean arterial oxygen saturation $\left(\mathrm{Sa}_{\mathrm{a}} \mathrm{O}_{2}\right)$ during walking and during resting in 24 patients with chronic obstructive pulmonary disease (COPD). The line of identity is shown.

$\mathrm{p}<0.01)$ and during walking $(\mathrm{r}=0.625 ; \mathrm{p}<0.01)$. No significant correlation was found between resting mean $\mathrm{Sa}_{\mathrm{a}} \mathrm{O}_{2}$ and the number of desaturations during meals, washing or walking.

\section{Discussion}

This is the first report of continuous recording of oxygen saturation during the day and night in patients with COPD not receiving supplemental oxygen. It shows that mean $\mathrm{Sa}_{\mathrm{a}} \mathrm{O}_{2}$ was lower during the night than during the day and that this pattern was present in most patients, as illustrated in figure 1. This observation is in agreement with previous studies using either arterial blood gas analysis or transcutaneous oximetry, and that showed development or worsening of hypoxaemia during sleep in COPD [3-7, 12]. Two studies compared nocturnal saturation with diurnal saturation measured during a rest of 15-30 min: mean and minimal $\mathrm{Sa}_{\mathrm{a}} \mathrm{O}_{2}$ correlated, but only weakly, thus preventing prediction of nocturnal saturation from diurnal values [16, 17]. Three mechanisms can explain nocturnal oxygen desaturations in COPD: the first is alveolar hypoventilation due to a diminution of ventilatory drive and an increase of upper airways resistance during non-rapid eye movement (NREM) sleep, together with an inhibition of intercostal and accessory inspiratory muscles during rapid eye movement (REM) sleep, the latter effect being particularly marked in hyperinflated patients with impaired diaphragmatic function. The second mechanism is an additional ventilation-perfusion mismatch, due to a decrease in functional residual capacity, and to regional hypoventilation, due to accumulation of bronchial secretions. Finally, some patients may have coexisting obstructive sleep apnoea.

In contrast to mean $\mathrm{Sa}_{\mathrm{a}} \mathrm{O}_{2}$, minimal $\mathrm{Sa}_{\mathrm{a}} \mathrm{O}_{2}$ was lower, and the number of $\mathrm{Sa}_{\mathrm{a}} \mathrm{O}_{2}$ falls was higher during the day than during the night. The pattern was heterogeneous, with a very low minimal $S \mathrm{a}, \mathrm{O}_{2}$ and a very high number of desaturations in some patients, as illustrated in figure 2. In some individuals, the number of desaturations was quite different during the day and the night. This may be explained by a different level of physical activity between patients, those being more active showing more desaturations during daytime. However, the protocol did not allow us to quantify the level of intensity of daily life activities to confirm this hypothesis. In the two other studies that reported prolonged diurnal and nocturnal $\mathrm{Sa}_{\mathrm{a}, \mathrm{O}_{2}}$ in COPD, SLIwINSKI et al. [19] found that mean and minimal $\mathrm{Sa}_{\mathrm{a}} \mathrm{O}_{2}$ were similar during day and night, and Estopa et al. [20] reported a higher mean and minimal $\mathrm{Sa}_{\mathrm{a}} \mathrm{O}_{2}$ during the night than during the day. It must be noted, however, that in both previous studies patients were on long-term oxygen therapy but spent part of the recording time without supplemental oxygen.

During the daytime, the results were quite similar in the whole group and in the group of 20 patients who took part in each type of activity. Walking was associated with the lowest mean $\mathrm{Sa}_{\mathrm{a}} \mathrm{O}_{2}$ and with the highest number of desaturations. This pattern was manifested by the majority of patients, with a few of them showing a particularly marked drop of mean $\mathrm{Sa}_{\mathrm{a}} \mathrm{O}_{2}$, as illustrated in figure 5. Oxygen desaturation is known to occur in COPD patients exercising even at a low level during cycling or walking tests $[23,24]$. This study shows that oxygen desaturation may also develop during free walking in daily life. Moreover, eating and washing, two other activities of daily living, were associated with frequent desaturations. During both eating and walking, the severity of desaturations, but not their number, was related to the mean saturation at rest. BROwn et al. [25] and ScHOLs et al. [26] reported transient desaturations during meals in COPD patients. In both studies, this occurred only in a subgroup of patients who were already hypoxaemic at rest. It can be hypothesized that irregularity of ventilation while chewing and swallowing causes ventilation-perfusion mismatch. Alveolar hypoventilation is unlikely because transcutaneous $\mathrm{PCO}_{2}$ was reported to remain stable during desaturations [26].

Nebulization therapy was associated with a high mean 
and minimal $\mathrm{Sa}_{\mathrm{a}} \mathrm{O}_{2}$ and a low number of desaturations, despite being administered without supplemental oxygen. Several mechanisms may explain this observation. Firstly, this therapy was administered while the patients were at rest, with their attention focused on breathing. Secondly, breathing through a mouthpiece has been shown to significantly increase ventilation both in healthy subjects and in asthmatic patients [27, 28]. Thirdly, the bronchodilator effect of salbutamol was likely to begin to develop during the nebulization period.

The technique of pulse oximetry has the advantage of providing a continuous and noninvasive assessment of oxygen saturation, but it also has some limitations. The major limitation is a relatively poor accuracy of $2-6 \%$ when compared to arterial blood measurements of oxygen saturation [29, 30]. However, if pulse oximetry is not accurate, it is quite reproducible in a given individual and reliably reflects changes in oxygen saturation at rest, during sleep or during exercise [29, 31]. In patients on long-term oxygen therapy, SLIwINSKi et al. [19] reported the highest number of desaturation periods during sleep, while having a nap, and watching television. On the contrary, we found the highest number of desaturations per hour in activities associated with motion, such as walking and washing. The latter observation raises the possibility of artefacts. This is, however, unlikely for the following reasons. Firstly, all periods suggesting artefacts because of abrupt changes in heart rate were excluded from analysis. These periods were generally easy to distinguish from the rest of the recording. Secondly, the number of desaturations was low during exercise training with supplemental oxygen (data not shown), although this situation was associated with a high level of motion and, therefore, a higher potential risk of artefacts.

In summary, this study shows that patients with moderate-to-severe chronic obstructive pulmonary disease may develop transient oxygen desaturation during daily activities associated with motion or irregular breathing, such as walking, washing and eating. In the majority of patients, the amplitude of desaturation was relatively small and of questionable haemodynamic consequence. However, it should be noted that resting hypoxaemia was present only in a minority of these patients, and was not profound. Due to the shape of the oxygen dissociation curve, deeper desaturations may be anticipated in daily life activities in patients who are slightly more hypoxaemic at rest.

\section{References}

1. Nocturnal Oxygen Therapy Trial Group. Continuous or nocturnal oxygen therapy in hypoxemic chronic obstructive lung disease. Ann Intern Med 1980; 93: 391398.

2. Report of the Medical Research Council Working Party. Long-term domiciliary oxygen therapy in chronic hypoxemic cor pulmonale complicating chronic bronchitis and emphysema. Lancet 1981; i: 681-685.

3. Coccagna G, Lugaresi E. Arterial blood gases and pulmonary and systemic arterial pressure during sleep in chronic obstructive pulmonary disease. Sleep 1978; 1: 117-124.

4. Douglas NJ, Calverley PMA, Legget RJE, et al. Transient hypoxemia during sleep in bronchitis and emphysema. Lancet 1979; i: 1-4.

5. Koo KW, Sax DS, Snider GL. Arterial blood gases and $\mathrm{pH}$ during sleep in chronic obstructive pulmonary disease. Am J Med 1975; 58: 663-670.

6. Wynne JW, Block AJ, Hemenway J, et al. Disordered breathing and oxygen desaturation during sleep in patients with chronic obstructive lung disease (COLD). Am J Med 1979; 66: 573-579.

7. Stradling JR, Lane DJ. Nocturnal hypoxaemia in chronic obstructive pulmonary disease. Clin Sci 1983; 64: 213-222.

8. Flick MR, Block AJ. Nocturnal versus diurnal cardiac arhythmias in patients with chronic obstructive pulmonary disease. Chest 1979; 75: 8-11.

9. Tirlapur VG, Mir MA. Noctural hypoxemia and associated electrocardiographic changes in patients with chronic obstructive airway disease. $N$ Engl J Med 1982; 306: 125-130.

10. Boysen PJ, Block AJ, Wynne JW, Hunt LA, Flick MR Nocturnal pulmonary hypertension in patients with chronic obstructive pulmonary disease. Chest 1979; 76: 536-542.

11. Fletcher EC, Levin DC. Cardiopulmonary hemodynamics during sleep in subjects with chronic obstructive pulmonary disease. Chest 1984; 85: 6-14.

12. Fletcher EC, Miller J, Divine GW, Fletcher JG, Miller T. Nocturnal oxyhemoglobin desaturation in COPD patients with arterial oxygen tensions above $60 \mathrm{mmHg}$. Chest 1987; 92: 604-608.

13. Fletcher EC, Luckett RA, Miller T, Fletcher JG. Exercise hemodynamics and gas exchange in patients with chronic obstruction pulmonary disease, sleep desaturation, and a daytime $\mathrm{Pa}_{\mathrm{a}} \mathrm{O}_{2}$ above $60 \mathrm{mmHg}$. Am Rev Respir Dis 1989; 140: 1237-1245.

14. Fletcher EC, Donner CF, Midgren B, et al. Survival in COPD patients with a daytime $P \mathrm{a}_{2} \mathrm{O}_{2}>60 \mathrm{mmHg}$ with and without nocturnal oxyhemoglobin desaturation. Chest 1992; 101: 649-655.

15. Fletcher EC, Luckett RA, Goodnight-White S, Miller CC, Qian W, Costarangos-Galarza C. A double-blind trial of nocturnal supplemental oxygen for sleep desaturation in patients with chronic obstructive pulmonary disease and a daytime $\mathrm{Pa}_{\mathrm{a}} \mathrm{O}_{2}$ above $60 \mathrm{mmHg}$. Am Rev Respir Dis 1992; 145: 1070-1076.

16. Connaughton JJ, Catterall JR, Elton RA, Stradling JR, Douglas NJ. Do sleep studies contribute to the management of patients with severe chronic obstructive pulmonary disease? Am Rev Respir Dis 1988; 138: 341-344.

17. Mohsenin V, Guffanti EE, Hilbert J, Ferranti R. Daytime oxygen saturation does not predict nocturnal desaturation in patients with chronic obstructive pulmonary disease. Arch Phys Med Rehab 1994; 75: 285-289.

18. Braggion C, Pradal U, Mastella G. Hemoglobin desaturation during sleep and daytime in patients with cystic fibrosis and severe airway obstruction. Acta Paediatr 1992; 81: 1002-1006.

19. Sliwinski P, Lagosz M, Gorecka D, Zielinski J. The adequacy of oxygenation in COPD patients undergoing longterm oxygen therapy assessed by pulse oximetry at home. Eur Respir J 1994; 7: 274-278.

20. Estopa RM, Monasterio C, Escarrabill J. Daily life desaturation in COPD patients on LTOT: International Oxygen Club multicentre European Study. Monaldi Arch Chest Dis 1993; 48(5): 426-428.

21. Siafakas NM, Vermeire P, Pride NB, et al. Optimal 
assessment and management of chronic obstructive pulmonary disease (COPD): a consensus statement of the European Respiratory Society. Eur Respir J 1995; 8: 1398-1420.

22. Hochberg Y, Benjamini Y. More powerful procedures for multiple significance testing. Stat Med 1990; 9: 811-818.

23. Dantzker DR, D'Alonzo GE. The effect of exercise on pulmonary gas exchange in patients with severe chronic obstructive pulmonary disease. Am Rev Respir Dis 1986; 134: 1135-1139.

24. Davidson AC, Leach R, George RJD, Geddes DM. Supplemental oxygen and exercise ability in chronic obstructive airways disease. Thorax 1988; 43: 965-971.

25. Brown SE, Casciari RJ, Light RW. Arterial oxygen saturation during meals in patients with severe chronic obstructive pulmonary disease. South Med J 1983; 76 : 194-198.

26. Schols A, Mostert R, Cobben N, Soeters P, Wauters E.
Transcutaneous $\mathrm{O}_{2}$ saturation and carbon dioxide tension during meals in patients with chronic obstructive pulmonary disease. Chest 1991; 100: 5: 1287-1292.

27. Askanazi J, Silverberg P, Foster R, Hyman A, MilicEmili J, Kinney J. Effects of respiratory apparatus on breathing pattern. J Appl Physiol: Respirat Environ Exercise Physiol 1980; 48: 577-580.

28. Freedman A, Lavietes M. Energy requirements of the respiratory musculature in asthma. Am J Med 1986; 80: 215-222.

29. Nickerson BG, Sarkisian C, Tremper K. Bias and precision of pulse oximeters and arterial oximeters. Chest 1988; 93: 515-517.

30. Clark JS, Votteri B, Ariagno RL, et al. Noninvasive assessment of blood gases. Am Rev Respir Dis 1992; 145: 220-232.

31. Escourrou PJL, Delaperche MF, Visseaux A. Reliability of pulse oximetry during exercise in pulmonary patients. Chest 1990; 97: 635-638. 